\title{
IDENTIFICATION OF ACTIVE AREAS OF EARTHQUAKE BY THERMAL REMOTE SENSING
}

\author{
Mohammad Ali Nezammahalleh ${ }^{\mathrm{a}}$, Abbas Ali Noori $^{\mathrm{b}}$, Hamideh Afsharmanesh $^{\mathrm{b}}$, Zahra Pourhosseini $^{\mathrm{c}}$, Abdolmotalleb Rastegar $^{\mathrm{d}}$, \\ Hoda Sadat Seyed Rezai ${ }^{\mathrm{e}}$, Seyed Kazem Alavipanah ${ }^{\mathrm{f}}$ \\ a * Dept. of Physical Geography, Geography Faculty, University of Tehran, Tehran, Iran \\ mnezammahalleh@ut.ac.ir \\ ${ }^{\mathrm{b}}$ Dept. of Geography, Kharazmi University, Tehran, Iran \\ (a_noori_63, afsharmanesh_hamideh)@yahoo.com \\ ${ }^{c}$ Dept. of Geography, Shahreray Islamic Azad University, Tehran, Iran \\ z.hoseini84@yahoo.com \\ ${ }^{\mathrm{d}}$ Dept. of Engineering and Technology, Golestan University, Aliabad Katool, Iran \\ amrastegara@yahoo.com \\ ${ }^{\mathrm{e}}$ Dept. of Space Research, Space Organization of Iran, Tehran, Iran \\ set_sr@yahoo.com \\ ${ }^{\mathrm{f}}$ Dept. of Remote Sensing and GIS, Geography Faculty, University of Tehran, Tehran, Iran \\ salavipa@ut.ac.ir
}

KEY WORDS: Thermal Remote Sensing, Seismology, Earthquake, Interpolation

\begin{abstract}
The study investigates the ability of thermal remote sensing in identification of seismic active areas. The thermal characteristics of Land Surface Temperature (LST) represent changes before strong earthquakes. The objective of this research is to find the relationship between earthquake active areas and thermal properties of earth surface. Landsat ETM+ images and earthquake points from USGS have been used as the material of the study. LST have been calculated by the image data and magnitudes of earthquake activity have been interpolated by the seismic point data. The study has found that the areas with higher LST values in long period have more seismic activity on central Alborz Mountain Range in Iran and that the areas along the major faults also have higher LST values.
\end{abstract}

\section{INTRODUCTION}

Based on the scientific evidence (Tronin et al., 2002; Tramutoli et al., 2005; Pulinets et al., 2006; Genzano et al., 2007; Saraf et al., 2009; Akhoondzadeh, 2013a; Tramutoli et al., 2013), the pressure before the occurrence of earthquakes can be represented by thermal anomalies or an increase in Land Surface Temperature (LST) (Saraf et al., 2009; Ouzounov and Freund et al., 2004). These anomalies were investigated in different areas of the world using thermal and infrared images (Tramutoli et al., 2013, Ouzounov et al., 2006). The first use of the thermal images in seismology was issued in 1988 (Alavipanah, 2003). Now, there are a plenty of evidence about thermal and heat signatures for prediction of earthquake probability (Pulinets et al., 2006; Tramutoli et al., 2013; Akhoondzadeh, 2013a), identification of seismologically active areas (Tramutoli et al., 2005; Genzano et al., 2007), and also about the mechanisms that generate thermal signals detectable for satellites (Pulinets et al., 2006; Freund et al., 2009). Some of the studies have attributed these anomalies to the gases exited from the fissures as a result of an enormous pressure (Tramutoli et al., 2013; Saraf et al., 2009), the contribution of groundwater (Ondoh, 2009; Saraf et al., 2009), and the exhaustion of gases like radon ionizing the air with changes in temperature and relative humidity (Zmazek et al., 2006; Saraf et al., 2009). Some theories such as positive pair holes have attempted to explain the interferences between the air and the land where led to an increase in LST (Saraf et al., 2009; Ouzounov and Freund et al., 2004; Akhoondzadeh, 2013b).
The happening of an earthquake may obviously cause considerable human and financial damages (Alcantara-Ayala, 2004). It is now impossible to prevent the event of an earthquake. The only way to avoid a catastrophe and undesirable detriments is to mitigate the adverse consequences and to adapt ourselves to the environment. This can be implemented by strengthening of the constructs (Shah and Dong, 1984), an appropriate site selection for human constructions and settlement (Ansal et al., 2010), and by identifying the vulnerable areas for precautious measures to minimize the damages (Walling and Mohanty, 2009). In this research we are to identify the earthquake active areas and classify them by the use of thermal remote sensing in Alborz mountain area. The hypothesis of the study is that the thermal changes due to seismic pressure in a long run can represent areas with more land surface temperature.

\section{MATERIALS AND METHODS}

As the material of the study we have used Landsat ETM+ in thermal range from 10.40 to 12.50 micron with a spatial resolution of 60 meters from USGS data, in path 163 and row 35 in acquisition of 2001. For earthquake data we also have searched the recorded seismologic data as the happened earthquakes from USGS EQ Archive for the period from 1973, as the beginning of instrumental records, to 2013. The earthquake attributes of depth, magnitude, date and time, and 
latitude and longitude coordinates are included in the data. For the elevation characteristics the SRTM data, 90 meters spatial resolution, have been used in this study. The faults of the area have been extracted from geologic map at scale 1:100000 from Iran Geological Organization. As the material, past earthquake events happened in Bushehr Province have been searched from for the period from 1973.

\subsection{Border of the study area}

In the methodology we isolated the border of the study area through a buffer with a radius of 70 kilometers, as an active distance for earthquake activity, from Kiasar in mountainous areas of Alborz. The study area is located in two provinces of Mazandaran and Semnan. (Figure 1)

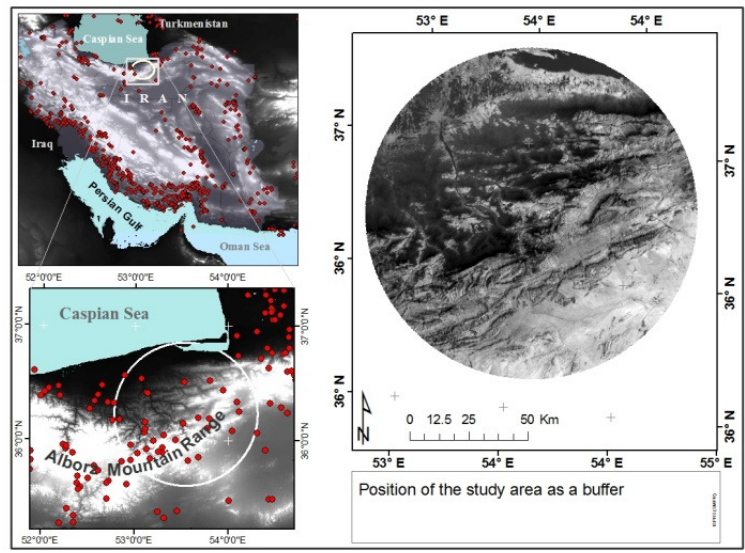

Figure 1: position of the study area in Alborz Mountain Range.

\subsection{Data preparation}

As the bands of Landsat are in 7 separated layers, the thermal band dimensions have been transformed in $30 \mathrm{~m}$ pixel sizes by nearest neighbor method and then layer stacked. As we have used Orthorectified images for the study. The earthquake points have been imported into ArcGIS.

\subsection{Retrieving LST}

Transforming Digital Number (DN) into Spectral radiance: The spectral radiance values from Landsat Project Scence Office data have been used for the transformation as the following formula:

$$
L_{\lambda}=\frac{L M A X-L M I N}{Q C A L M A X-Q C A L M I N} \times(Q C A L-Q C A L M I N)+L M I N
$$

Where QCALMIN is the smallest DN (1) and QCALMAX is the largest DN (255); the QCAL is DN in given pixel; LMIN is spectral radiance value in DN zero of band 6 and LMAX is that for DN 255. LMIN and LMAX values have been extracted from header file of the image.

Transforming Spectral radiance into back body temperature: The thermal data of ETM+ is transformed from spectral radiance to back body temperature that spectral radiance of 1 is assumed as the highest radiance (Landsat Project Science Office, 2002). So the formula is:

$$
T_{B}=\frac{K_{2}}{\ln \left(\frac{K_{1}}{L_{\lambda}}+1\right)}
$$

Where $T_{B}$ is the satellite effective temperature in Kelvin $\left(K^{0}\right)$; $K_{1}$ is the first calibration constant equal to 666 and $K_{2}$ is the second calibration constant equal to $1282\left(\mathrm{~K}^{\mathrm{o}}\right) ; \mathrm{L}_{\lambda}$ is spectral radiance for the given pixel.

Emissivity correction: For accurate retrieval of LST it is needed to correct the emissivity (Alavipanah, 2006). The correction can be executed by Normalized Difference Vegetation Index (NDVI) Threshold Method (Sobrino et al., 2004; Hashemi et al., 2012). This has classified NDVI values as bare lands $\left(\mathrm{NDVI}<0.2, \quad \varepsilon_{\text {Soil }}=0.97\right)$, vegetation area (NDVI $\left.>0.5, \varepsilon_{\mathrm{Veg}}=0.99\right)$, and areas with mixture of vegetation and bare lands $(0.2 \geq \mathrm{NDVI} \leq 0.5) ; \varepsilon_{\text {Mix }}$ is calculated as below:

$$
\mathcal{E}=\varepsilon_{V e g} P_{v}+\varepsilon_{\text {Soil }}\left(1-P_{V}\right)
$$

Where $P_{v}$ is the vegetation coefficient that can be calculated by the following relation:

$$
P_{v}=\left(\frac{N D V I-N D V I_{\min }}{N D V I_{\max }-N D V I_{\min }}\right)
$$

Where $\mathrm{NDVI}_{\min }=0.2$ and $\mathrm{NDVI}_{\max }=0.5$, with emissivity values available, LST is calculated as the following:

$$
L S T=\frac{T_{B}}{1+\left(\lambda \times T_{B} / \rho\right) \ln \varepsilon}
$$

Where $\lambda$ is the wavelength of the emitted radiance $(\mu \mathrm{m}), \rho$ is equal to $1.438 \times 10^{-2}$, and $\varepsilon$ is emissivity. The obtained temperature map is converted form units of Kelvin into units of degree centigrade so that the number 173.15 is subtracted from the map in Kelvin.

NDVI calculation: The index is calculated using red and near infrared range of electromagnetic spectrum. For ETM+ Image this is calculated as below:

$$
N D V I=\frac{\rho(\text { band } 4)-\rho(\text { band } 3)}{\rho(\text { band } 4)+\rho(\text { band } 3)}
$$

Where band 4 and band 3 are Infrared and Red ranges in ETM+, respectively; $\rho$ is reflectance values of the bands (Landsat Project Science Office, 2002). The reflectance is obtained as:

$$
\rho_{P}=\frac{\pi \cdot L_{\lambda} \cdot d^{2}}{E S U N_{\lambda} \cdot \cos \theta_{S}}
$$

Where $\rho$ in reflectance coefficient of the band, $L_{\lambda}$ is spectral radiance, $d$ is the distance of earth to sun in astronomic units, ESUN $_{\lambda}$ is mean solar exoatmospheric irradiance, $\theta$ is zenith angle of the sun (Nezammahalleh et al., 2010; Landsat Project Science Office, 2002). 


\subsection{Seismic interpolation}

Kringing is an interpolation method that uses statistical models that have many map outputs. The interpolation is with the assumption that data come from stationary stochastic process and are normally distributed. Polynomial Interpolation (LPI) is a deterministic interpolator. The earthquake points from USGS Catalog have been interpolated by the Ordinary Kringing (OK) and the Local Polynomial Interpolation (LPI) and exported as raster layer.

\section{RESULTS AND DISCUSSION}

The LST map shows that southeast parts of the area have higher temperature and the temperature decrease towards the northwest. Southern slopes of Alborz have higher temperature values (Figure 2). Although these temperature trends may be as a result of the aspects of Alborz Mountain Range towards the sun shines in the southern slopes, they have changes coincident with the directions of main faulting in the mountain.

The areas of more LST values can be observed along Khazar Fault in the north of the area and also along Alborz Shomali Fault in the center of the study area in the north east to south west direction. In the southern half of the later fault LST values are higher than the areas in the north of the fault.

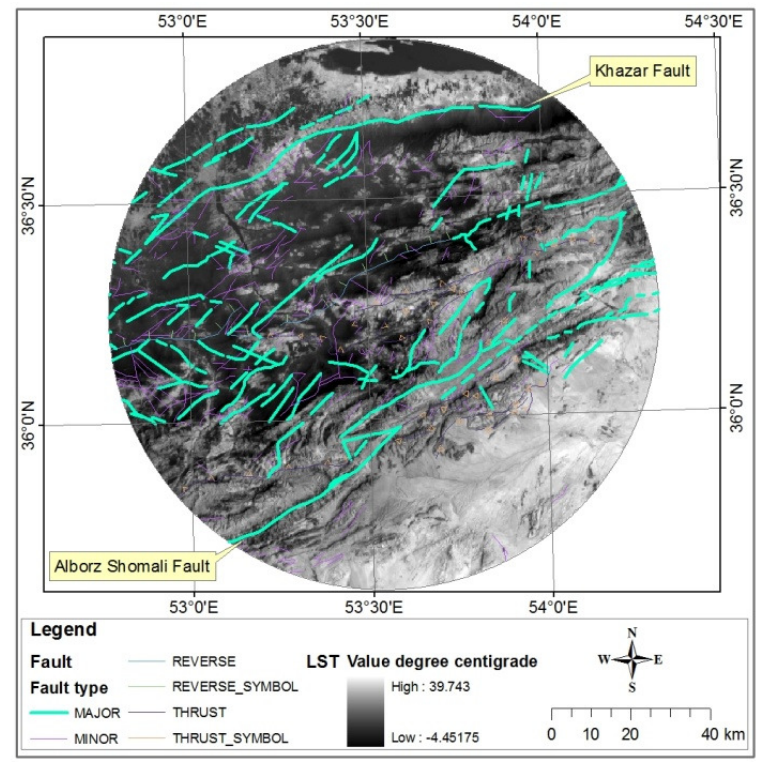

Figure 2: the map of LST from Landsat thermal bands

The interpolated map by OK indicates higher seismic activities on the southern slopes of Alborz Mountain Range. In the southeast of the buffer of the area the highest values of earthquake magnitudes can be observed (Figure 3). According to this illustration the southern and southeastern portions of the study area have more seismic activity. The only exception about this can be the south of the study area where the magnitude interpolation shows lower seismic activity.

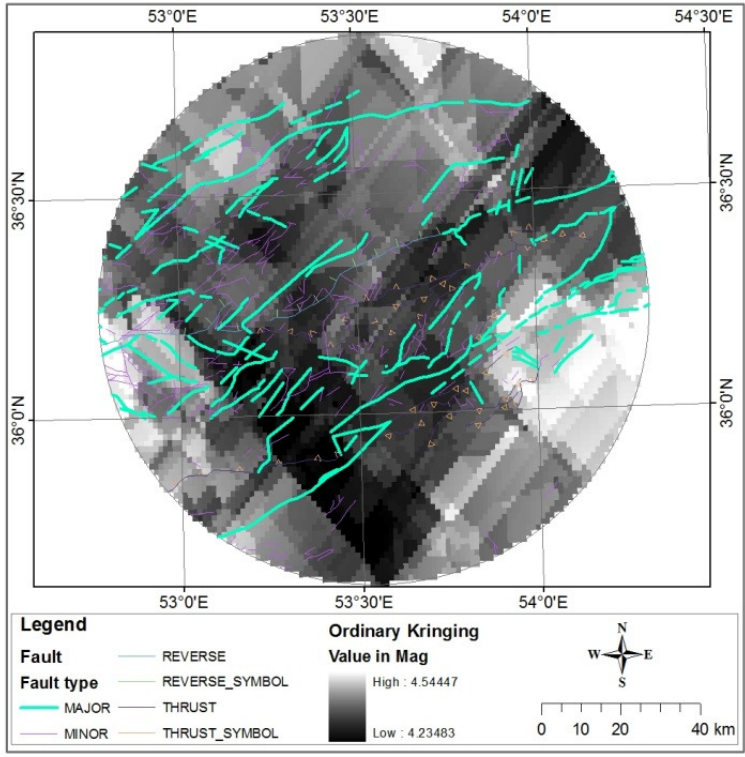

Figure 3: interpolated map of seismic activity by OK method

The LPI map also shows a trend that decrease in pixel values, i.e., higher magnitude values in earthquake, just from southeast portions of the area towards the northwest areas (Figure 4).

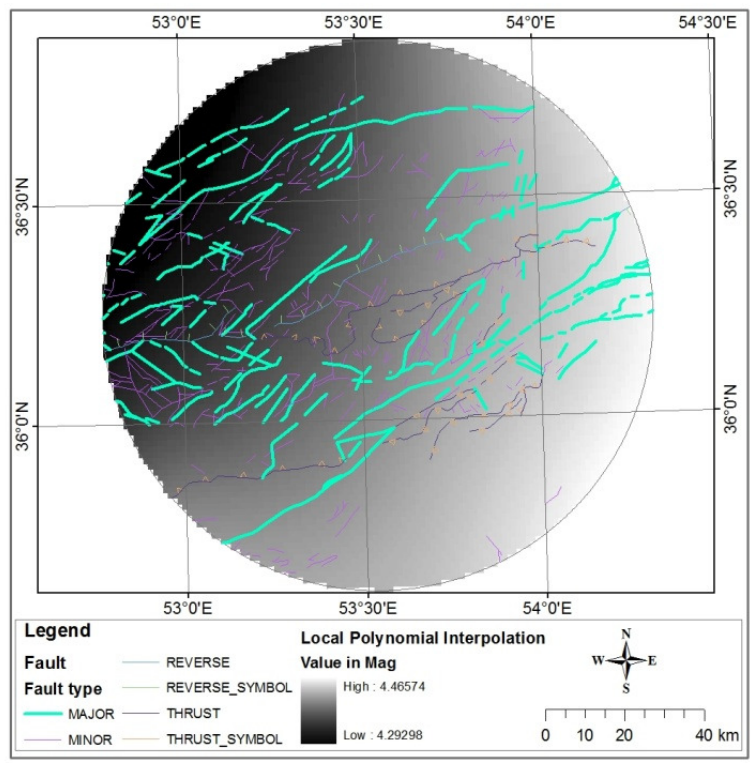

Figure 4: interpolated map of seismic activity by LPI method

Overlaying the raster of earthquake magnitude and thermal classification, it has been revealed that as thermal pixel values decrease in a direction from southeast to northwest, the same trend can be observed in earthquake magnitude. The southeast portion of the area, as it can be seen in the Figure 1, Figure 2 and Figure 3, is high in both the thermal conditions and in seismic activity. Within the border of the study area about 29 earthquakes were recorded in a 40 years period. Up to 11 earthquakes with an average magnitude of 4.33 were recorded in the classes with higher thermal values and about 18 with average magnitude of 4.11 in classes with low thermal values. There may be some other factors that interfere in theses 
interpretations. For instance, in this research the trend of heat and magnitude were coincident with the topography of the area from elevation data of SRTM (Figure 5).

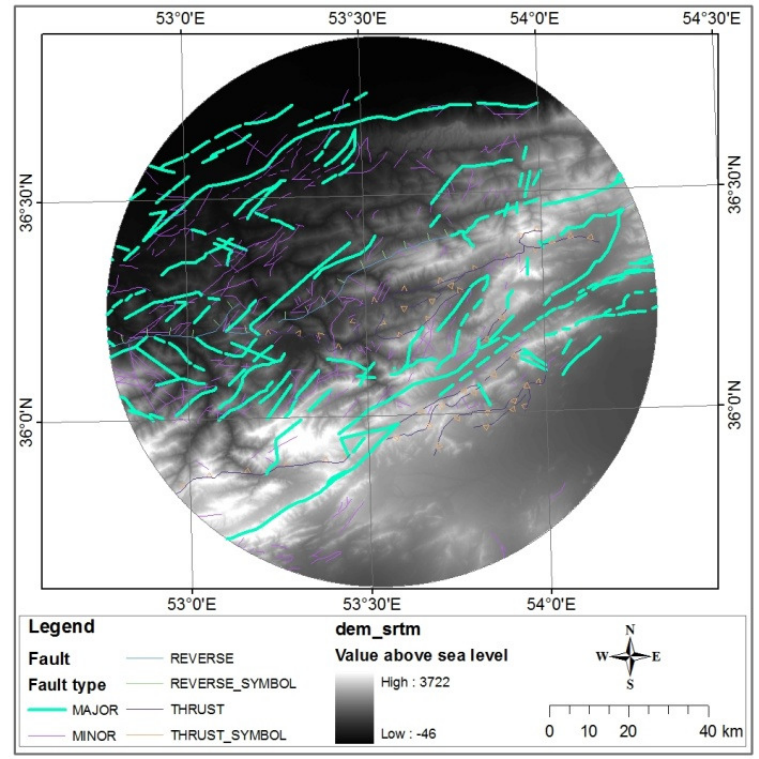

Figure 5: topographical terrain of the study area from SRTM data

Although we have not considered some possible interfering controls in this study, this method using thermal remotely sensed data can be applied to identify the active areas of earthquake. Results of interpolation indicate that the pixels with higher values of magnitude are over the pixels with higher LST values. According to the pixel values it can be observed that in the far west end of the study area where the thermal values are the highest, the values of earthquake magnitude are also the highest. Thus, seismic active areas have excess infrared intensity in a long time before seismic activity (Saraf et al., 2009) and in this period the area may represent higher LST values. In a portion in the north of the area covered by a water body (Gorgan Bay), the magnitude raster represents high values while the thermal is low in value and this can be because of the moderating factor of water. There can be somewhat higher LST values along the line Khazar Major Fault in the northern part of the study area and also along Alborz Shomali Fault in the southern of the study area (refer to Figure 2). Saraf et al., (2009) also found that the LST increases in tectonic contact-faced areas. Therefore, we can see higher land surface temperature in areas along the fault lines (Ma et al., 2010) and over more active seismic parts.

\section{CONCLUSION}

The results of the study indicate that the areas with higher LST values are coincident with the areas of more seismic activity on the study area. The Ordinary Kringing and Local Polynomial Interpolation methods have both been applied to interpolate the magnitude of recorded earthquake. According to these interpolations, it can be stated that the southeast portions of the study area have experienced earthquakes with higher magnitude relative to other parts of the area. The northern portions have experienced lower earthquake magnitudes. The LST map has revealed that the same areas with high earthquake magnitude have higher LST relative to their surrounding areas. It may be possible to estimate seismic active areas by LST and thermal anomalies.

\section{References}

Akhoondzadeh, M., 2013a, An adaptive Network-based Fuzzy Inference System for the detection of thermal and TEC anomalies around the time of Varzeghan, Iran, $\left(\mathrm{M}_{\mathrm{w}}=6.4\right)$ earthquake of 11 August 2012, Advances in Space Research 52, $837-852$

Akhoondzadeh, M., 2013b, Genetic algorithm for TEC seismoionospheric anomalies detection around the time of Solomon $\left(M_{w}=8\right)$ earthquake of 06 February 2013, Advances in Space Research 52, 581-590

Alavipanah, S.K.; 2002, Application of remote sensing in earth science (Soil Science), University of Tehran Press, 40

Alcantara-Ayala, I., 2002, geomorphology, natural hazards, vulnerability and prevention of natural disasters in developing countries, Geomorphology 47, 107-124

Ansal, A.; Kurtulus, A.; Tonuk, G., 2010, Seismic microzonation and earthquake damage scenarios for urban areas, Soil Dynamic and Earthquake Engineering 30, 1319-1328

Freund, F.T.; Kulahci, I.G.; Cyr, G.; Ling, J.; Winnick, M.; Tregloan-Reed, J.; Freund, M.M., 2009, Air ionization at rock surfaces and pre-earthquake signals, Journal of Atmospheric and Solar-Terrestrial Physics 71, 1834-1834

Genzano, N.; Aliano, C.; Filizzola, C.; Pergola, N.; Tramutoli, V., 2007, A robust satellite technique for monitoring seismically active areas: The case of Bhuj-Gujarat earthquake, Tectonophysics 431, 197-210

Hashemi, S.M.; Alavipanah, S.K.; Dinaroudi, M., 2012, Investigation of land surface temperature distribution in urban area by remote sensing, Environmnetology 39, 81-92 (in Farsi)

Ma, J.; Chen, S.; Hu, X.; Liu, P., Liu, L., 2010, Spatial-temporal variation of the land surface temperature field and present day tectonic activity, Geoscience Frontiers 1, 57-67

Nezammahalleh, H.; Farhadi, F.; Tanhaemami, M., 2010, Conceptual design and techno-economic assessment of integrated solar combined cycle system with DSG technology, Solar Energy 84, 1696-1705

Ondoh, T., 2009, Investigation of precursory phenomena in the ionosphere, atmosphere and groundwater before large earthquakes of $M>6.5$, Advances in Space Research 43, 214 223

Ouzounov, D.; Bryant, N.; Logan, T., 2006, Satellite thermal IR phenomena associated with some of the major earthquakes in 1999-2003, Physics and Chemistry of the Earth 31, 154-163

Ouzounov, D.; Freund, F., 2004, Mid-infrared emission prier to strong earthquakes analyzed by remote sensing data, Advances in Space Research 33, 268-273

Pulinets, S.A.; Ouzounov, D.; Karelin, A.V.; Boyarchuk, K.A.; Pokhmelnykh, L.A., 2006, The physical nature of thermal 
anomalies observed before strong earthquakes, Physics and Chemistry of the Earth 31, 143-153

Saraf, A.K.; Rawat, V.; Choudhury, S.; Dasgupta, S.; Das, J., 2009, Advances in understanding of the mechanism for generation of earthquake thermal precursors detected by satellites, International Journal of Applied Earth Observation and Geoinformation 11, 373-379

Shah, H.C.; Dong, W.M., 1984, reliability assessment of existing buildings subjected to probabilistic earthquake loadings, Soil Dynamic and Earthquake Engineering 3, 35-41

Sobrino, A.J.; Jimenez-Munoz, J.C.; Paolini, L., 2004, Land surface temperature retrieval from LANDSAT TM 5, Remote Sensing of Environment 90, 434-440

Tramutoli, V.; Aliano, G.; Corrado, R.; Filizzola, C.; Genzano, N.; Lisi, M.; Martinelli, G.; Pergola, N., 2013, On the possible origin of thermal infrared radiation (TIR) anomalies in earthquake-prone areas observed using robust satellite techniques (RST), Chemical Geology 339, 157-168

Tramutoli, V.; Cuomo, V.; Filizzola, C.; Pergola, N.; Pietrapertosa, C., 2005, Assessing the potential of thermal infrared satellite surveys for monitoring seismically active areas: The case of Kocaeli (Izmit) earthquake, August 17, 1999

Tronin, A.A.; Hayakawa, M.; Molchanov, O.A., 2002, thermal IR satellite data application for earthquake research in Japan and China, Journal of Geodynamics 33, 519-534

Walling, M.Y.; Mohanty, W.K., 2009, An overview on seismic zonation and microzonation studies in India, Earth-Science Reviews 96, 67-91

Zmazek, B.; Todorovski, L.; Zivcic, M., Dzeroski, S.; Vaupotic, J.; Kobal, I., 2006, Radon in a thermal spring: Identification of anomalies related to seismic activity, Applied Radiation and Isotopes $64,725-734$

\section{Ackowledgement}

The authors would like to thank greatly Mr. Hassan Nezammahalleh for preparing Formula and proof reading the manuscript. The financial support of University of Tehran is also greatly appreciated. 